\title{
Katalin Juhász (1952-2012)
}

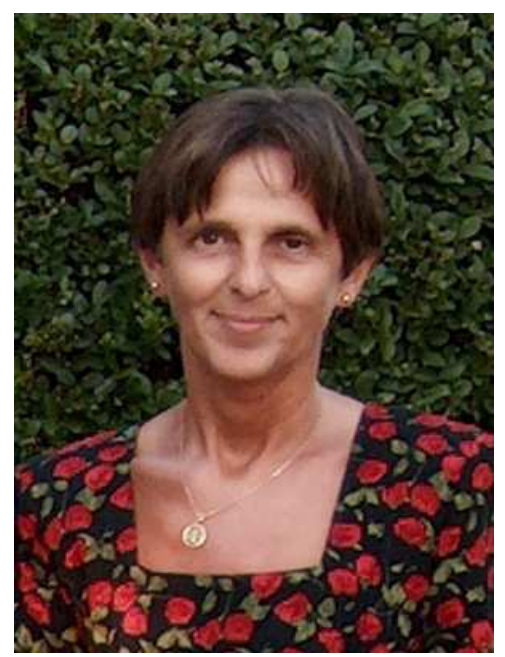

Katalin Juhász was born in 1952, in Tarnaméra (Hungary), where she also completed her primary school studies. She finished Erzsébet Szilágyi Highschool, Eger, in 1971 and she graduated in mathematics from Lajos Kossuth University (KLTE), Debrecen, in 1976. That year she married a physicist and together they brought up their son.

She started to work at the Institute of Nuclear Research of the Hungarian Academy of Sciences (ATOMKI) in 1976, where she was involved in developing mathematical methods and their computer implementations needed for the theoretical nuclear physics research in progress that time. During that time she also worked, without a supervisor, on the subject of her dissertation for the Doctor of the Univ. degree, which she defended "Summa cum laude" in 1981. Based on that and her further research activity she obtained a PhD degree in 1999. During her work in ATOMKI she studied and became familiar with various levels of computer programming related, among others, to developments in microprocessor based electronics as well as to medical and biological research.

In 1988 she decided to utilize her computing experience in higher education. She became a senior lecturer, and then an associate professor at Ferenc Kölcsey Teacher Training College, Debrecen. Besides her activity in creating and improving the technical basis of teaching informatics in the College, she initiated and helped elaborate the curriculum of teaching computer science in primary schools. 
In 1993 she moved to work at Lajos Kossuth University (University of Debrecen, from 2000) where she worked until her retirement in 2011. First she was a senior lecturer in the Institute of Mathematics and Informatics (IMI), then she became an associate professor of the Faculty of Informatics in 2003. She was mainly involved in the training of teachers in computer science, but she also actively took part in the education of foreign students. She started and deepened her research work in the methodology and didactics of teaching computer science, in particular, in fields related to computer aided teaching and education. She became a consultant in this field, was the leader of the ECDL Examination Center, and had essential work in settling the SunSITE Hungary, the most developed server of the Sun Microsystems at that time, to the IMI. She organized several conferences and was the member of the program committee of several local and regional meetings, such as Multimedia in Education. She actively supervised the work of about $10 \mathrm{PhD}$ students in the PhD School for Mathematics and Computational Sciences as well as in the Doctoral School of Informatics at the University of Debrecen. Four of these students have already obtained their PhD degree, while another four have completed the credit requirements of these doctoral schools.

Besides her educational activity, from 2000, she participated in various scientific collaborations partly within the research programs of ATOMKI in nuclear physics, and partly initiated by her. She was the Hungarian leader of one of the projects, the one aiming at IT developments related to accelerator physics and applications, carried out within the framework of bilateral inter-governmental science and technology cooperations with the South African iThemba LABS (near Cape Town). Not only did she contribute to the development of computer codes and to the solving of computational problems in the acquisition and analysis of data obtained in nuclear physics experiments using large gamma-ray spectrometer arrays, but she also took part in many of the experiments, especially those in which a charged particle ancillary detector system, developed with her participation in ATOMKI, was also utilized.

She authored and coauthored more than 100 publications mainly published in refereed journals and conference proceedings. She got several prizes for her exceptional activity and work of high standard: among others, in 2005 she obtained the Tarján Memorial Prize from the John von Neuman Computer Science Society, and in 2011 she was awarded the Medallion for Educational Service by the Ministry of National Resources.

She was a founding member of the editorial board of the journal Teaching Mathematics and Computer Science and she was the technical editor of this journal until her death on 16th December, 2012.

Katalin Juhász was a talented, honest and helpful person with a cheerful and warmhearted attitude. Being sociable and sensitive she had a passion for traveling and was devoted to music and literature. She still had many plans when her health failed her. A grave illness, a malignant disease diagnosed in 2009, struck her. With her untimely death the Institute of Mathematics, the Faculty of Informatics, the journal Teaching Mathematics and Computer Science and the University of Debrecen lost an outstanding teacher and an eminent colleague. 